\title{
Comparison of brain maturation among species: an example in translational research suggesting the possible use of bumetanide in newborn
}

\author{
Ronit Pressler ${ }^{1,2}$ and Stéphane Auvin ${ }^{3,4,5 *}$ \\ 1 Institute of Child Health, University College London, London, UK \\ 2 Department of Clinical Neurophysiology, Great Ormond Street Hospital, London, UK \\ 3 INSERM, U676, Paris, France \\ 4 INSERM UMR676, Université Paris Diderot, Paris, France \\ ${ }_{5}$ Service de Neurologie Pédiatrique, APHP, Hôpital Robert Debré, Paris, France \\ *Correspondence: auvin@invivo.edu \\ Edited by: \\ Patrick A. Forcelli, Georgetown University, USA
}

The therapeutic need for neurological diseases requires the pursuit of research in this area by the development of new models of brain diseases as well as preclinical drug studies. Among them, the development of medicines for newborns has been identified as an urgent need for both preclinical and clinical research (Silverstein et al., 2008). This would lead to more translational studies on the developing brain. However, there are certain risks involved in this translation from animal models to humans such as the effect on brain maturation, safety, and co-morbidity. Interpretation of results of preclinical drug studies requires a knowledge of brain maturation among species in particular when the efficacy or the safety of a drug may be different. Moreover, the risk benefit ratio of a drug in development should also be considered in the interpretation of translational studies.

The use of animal models in experimental studies has led to a dramatic increase in our knowledge. Rodents are the most frequently used species in both experimental and translational studies. In the field of developmental neuroscience several differences between human and laboratory rodent brain maturation are well recognized, but determining the exact equivalences in developmental milestones between species is a multidimensional task and a single answer is not always possible.

To put experimental data into clinical context, brain maturation among species is compared using various criteria such as cerebral growth, neurogenesis, synaptogenesis, and other variables (Table 1). These comparisons are done to propose translational research on the human developing brain. Using neurogenesis as a criterion, it has been shown that E18 and E21 rat brain match with week 8-9 and week 15-16 after fertilization in the human embryo, respectively (Bayer et al., 1993). But the timing of neurogenesis differs substantially across brain regions increasing the challenge to compare brain maturation between species. Moreover, most of the neuronal/astrocytic migration ends at 20 weeks of gestation (WG) in humans while this process is mainly observed between E19 and E21 in rats (Raedler et al., 1980). Other parameters such as functional measures could be used to evaluate postnatal development. As an example, the age at which the ability to move is achieved can be compared. Locomotion in the rat matures during the first few weeks after birth. Rat pups are able to ambulate through the use of their forelimbs, upper torso and head beginning around P3-P4. This "crawling" behavior peaks around P7 and disappears around P15. It is not until around P8-P10 that rat pups can stand with their abdomens completely off the floor. Around P12-P13, rat pups can walk while supporting their full weight, but the hindlimbs are typically rotated outward (Wood et al., 2003). In human infants, the last stage before walking around at 13 months of age typically involves intermittently placing one foot flat on the floor and creeping like a bear on hands and feet. Interestingly, an infant can bear his full weight (i.e., stand) while being held by her hands by $24-28$ weeks and can walk while holding onto a piece of furniture by 48 weeks (Wood et al., 2003).
Using several criteria, some authors have suggested a 12-13-day-old rat pup cerebral cortex can be compared to a term human newborn (Romijn et al., 1991).

Reviewing these data on brain development, we think that the recent data published by Wang and Kriegstein (2011) don't provide any argument against the use of bumetanide in the human neonate. Wang and Kriegstein used different protocols of bumetanide administration in four different age groups showing that the early life blocking $\mathrm{Na}^{+}-\mathrm{K}^{+}-2 \mathrm{Cl}^{-}$co-transporter (NKCC1) with bumetanide disrupts the balance of excitatory and inhibitory synapses in the cortex of adult mice. These effects were shown in two of the treated groups. These groups received daily systemic injections of $0.2 \mathrm{mg} / \mathrm{kg}$ of bumetanide from the 15th day of gestation (E15) to the 7th postnatal day (P7) or from E17 to P7. Interestingly, no difference in the synapse excitability was observed when the mice became adult in the two other groups which were treated with bumetanide after birth (P0-P7 and P7-P14). The altered neurotransmission in adult mice that were exposed to bumetanide early in life (E15-P7 and E17-P7) was correlated with modifications of neuron morphology as well as behavior modifications. Behavior studies were conducted in adult mice from the E15-P7 group. Long-term consequences were observed such as developmental delay and impairment in sensorimotor gating. Similar findings were observed with other antiepileptic drugs (Forcelli et al., 2012a,b).

Bumetanide is a loop diuretic with a rapid onset and short duration of action blocking the renal NKCC1 co-transporter. 
Table 1 | Comparative development of the cortex between laboratory rodents and humans using various criteria.

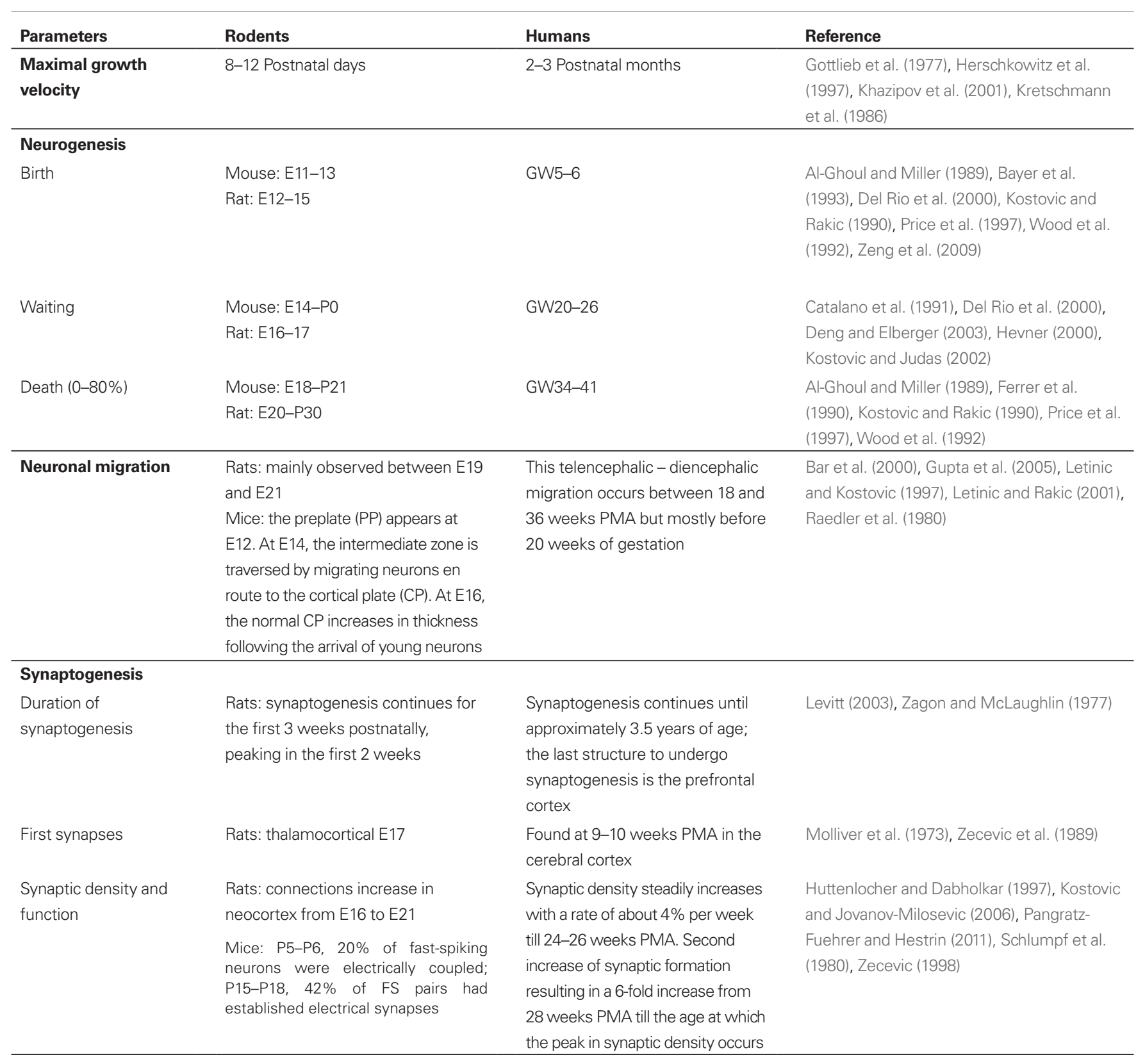

Bumetanide is also able to block the neuronal NKCC1 co-transporter which is thought to be involved in the excitatory action of GABA in the immature brain (Ben-Ari and Holmes, 2006). The expression of NKCC1 in the developing brain starts embryonically in both human (gestational age of 20 weeks $=$ GA20) and mouse (E12) but the peak of expression is prenatal in human (GA35) while it is postnatal in mice (P7) (Dzhala et al., 2005). Moreover, it has been shown that NKCC1 is increased by experimental hypoxic seizures in the developing brain (Cleary et al., 2013). It has been shown that bumetanide reduces neuronal firing in immature neurons using hippocampal slices (Dzhala et al., 2005) or intact hippocampus (Kilb et al., 2007). In vivo models studies have also shown the effect on seizure of bumetanide in both the kainate model (Dzhala et al., 2005) and the PTZ model in rat pups (Mares, 2009). Moreover, antiepileptogenic properties have been reported using the rapid kindling model in rat pups (Mazarati et al., 2009). Clinical trials in neonates are under way in the US (Harvard Medical School Boston, personal communication) and with the NEMO study about to start in Europe (EU FP7 funded collaborative project). A recent single case report in a 6-week-old baby has shown that bumetanide can reduce seizure duration and frequency with no clinical or metabolic side effects (Kahle et al., 2009).

However, Wang and Kriegstein (2011) concluded that "our data suggest caution for long-term use of bumetanide to treat neonatal seizures." We think this is a rather inappropriate postulation as their data do 
not provide evidence against the use in term babies and it neglects the risk benefit ratio of antiepileptic drugs in this age group.

Although seizures in the immature brain do not cause the same neuronal damage as in the mature brain, it is now evident that seizures in early life interfere with the development of neuronal circuits thereby increasing the risk for subsequent seizures and adverse behavioral outcome (Holmes, 2005; Ben-Ari and Holmes, 2006). Furthermore, seizures can increase perinatal hypoxic brain damage (Miller et al., 2002) and can lead to later cognitive or neurological deficits (Ronen et al., 2007). The treatment of neonatal seizures has not changed over the last several decades and the first line antiepileptic drug for neonatal seizures remains phenobarbitone (Blume et al., 2009; Vento et al., 2010), despite the fact that phenobarbitone has show only limited efficacy in the neonatal period (Painter et al., 1999; Boylan et al., 2004). A Cochrane (Booth and Evans, 2004) showed that there is little evidence from randomized trials to support the use of any AED currently in use in the neonatal period. Furthermore most of the older antiepileptic drugs used, in particular phenobarbitone and phenytoin, increase neuronal apoptosis (Bittigau et al., 2002) and this may further increase neuronal insult. This effect has not been found with newer antiepileptic drugs such as levetiracetam (Kim et al., 2007).

In contrast to hundreds of studies in the adult population the efficacy and safety of newer antiepileptic drugs in newborn babies has not been adequately studied. This is due to the specific technical (biological sampling, assessment of drug effect), logistic (recruitment), and financial (cost too high for a small market) as well as legal (informed consent) difficulties (Chiron et al., 2008). This gives rise to an ethical predicament: babies should be protected from the potential risks of research but they may be harmed when given inadequately studied medicines and/or fail to benefit from more effective and less harmful newer agents. The lack of new antiepileptic drugs for neonatal seizures stands in contrast to a growing understanding of the different mechanisms that explain the susceptibility to seizures and the lack of response to conventional anticonvulsants (Ben-Ari and Holmes, 2006; Jensen, 2009). This knowledge presents important new possibilities for novel age-specific therapeutic strategies. One important example is the above mentioned finding that GABA has excitatory properties in the immature brain which may be susceptible to treatment with bumetanide (Dzhala et al., 2005). The above mentioned clinical trials on the efficacy of bumetanide are the first steps toward high standard, multicenter trials using innovative methods to improve outcome for neonates at risk for acute and long-term neurologic damage from neonatal seizures.

A large amount of data on the brain maturation in the various species show the complexities of developmental timing. It seems that laboratory rodent $\mathrm{P} 0$ matches with the antenatal or early premature human baby. Based on these, it is clear that the issue of bumetanide safety is still open. Inappropriate or premature caution against bumetanide trials could have far reaching consequences for a potentially beneficial drug for neonatal seizure while this drug has been widely used in neonates for nonseizure conditions.

\section{ACKNOWLEDGMENT}

R. Pressler is partially supported by funding from the (European Community's) Seventh Framework Program (FP7/2007-2013) under grant agreement no. (241479). S. Auvin is partially supported by an INSERM grant (Contrat Interface INSERM 2010).

\section{REFERENCES}

Al-Ghoul, W. M., and Miller, M. W. (1989). Transient expression of Alz-50 immunoreactivity in developing rat neocortex: a marker for naturally occurring neuronal death? Brain Res. 481, 361-367.

Bar, I., de, R. C., and Goffinet, A. M. (2000). The evolution of cortical development. An hypothesis based on the role of the Reelin signaling pathway. Trends Neurosci. 23, 633-638.

Bayer, S. A., Altman, J., Russo, R. J., and Zhang, X. (1993). Timetables of neurogenesis in the human brain based on experimentally determined patterns in the rat. Neurotoxicology 14, 83-144.

Ben-Ari, Y., and Holmes, G. L. (2006). Effects of seizures on developmental processes in the immature brain. Lancet Neurol. 5, 1055-1063.

Bittigau, P., Sifringer, M., Genz, K., Reith, E., Pospischil, D., Govindarajalu, S., et al. (2002). Antiepileptic drugs and apoptotic neurodegeneration in the developing brain. Proc. Natl. Acad. Sci. U.S.A. 99, 15089-15094.

Blume, H. K., Garrison, M. M., and Christakis, D. A. (2009). Neonatal seizures: treatment and treatment variability in 31 United States pediatric hospitals. J. Child Neurol. 24, 148-154.

Booth, D., and Evans, D. J. (2004). Anticonvulsants for neonates with seizures. Cochrane Database Syst. Rev. 18, CD004218.
Boylan, G. B., Rennie, J. M., Chorley, G., Pressler, R. M., Fox, G. F., Farrer, K., et al. (2004). Second-line anticonvulsant treatment of neonatal seizures: a video-EEG monitoring study. Neurology 62, 486-488.

Catalano, S. M., Robertson, R. T., and Killackey, H. P. (1991). Early ingrowth of thalamocortical afferents to the neocortex of the prenatal rat. Proc. Natl. Acad. Sci. U.S.A. 88, 2999-3003.

Chiron, C., Dulac, O., and Pons, G. (2008). Antiepileptic drug development in children: considerations for a revisited strategy. Drugs 68, 17-25.

Cleary, R. T., Sun, H., Huynh, T., Manning, S. M., Li, Y., Rotenberg, A., et al. (2013). Bumetanide enhances phenobarbital efficacy in a rat model of hypoxic neonatal seizures. PLoS ONE 8:e57148. doi: 10.1371/ journal.pone.0057148

Del Rio, J. A., Martinez, A., Auladell, C., and Soriano, E. (2000). Developmental history of the subplate and developing white matter in the murine neocortex. Neuronal organization and relationship with the main afferent systems at embryonic and perinatal stages. Cereb. Cortex 10, 784-801.

Deng, J., and Elberger, A. J. (2003). Corticothalamic and thalamocortical pathfinding in the mouse: dependence on intermediate targets and guidance axis. Anat. Embryol. 207, 177-192.

Dzhala, V. I., Talos, D. M., Sdrulla, D. A., Brumback, A. C., Mathews, G. C., Benke, T.A., et al. (2005). NKCC1 transporter facilitates seizures in the developing brain. Nat. Med. 11, 1205-1213.

Ferrer, I., Bernet, E., Soriano, E., del, R. T., and Fonseca, M. (1990). Naturally occurring cell death in the cerebral cortex of the rat and removal of dead cells by transitory phagocytes. Neuroscience 39, 451-458.

Forcelli, P. A., Janssen, M. J., Vicini, S., and Gale, K. (2012a). Neonatal exposure to antiepileptic drugs disrupts striatal synaptic development. Ann. Neurol. 72, 363-372.

Forcelli, P.A., Kozlowski, R., Snyder, C., Kondratyev,A., and Gale, K. (2012b). Effects of neonatal antiepileptic drug exposure on cognitive, emotional, and motor function in adult rats. J. Pharmacol. Exp. Ther. 340, 558-566.

Gottlieb, A., Keydar, I., and Epstein, H. T. (1977). Rodent brain growth stages: an analytical review. Biol. Neonate 32, 166-176.

Gupta, R. K., Hasan, K. M., Trivedi, R., Pradhan, M., Das, V., Parikh, N. A., et al. (2005). Diffusion tensor imaging of the developing human cerebrum. J. Neurosci. Res. 81, 172-178.

Herschkowitz, N., Kagan, J., and Zilles, K. (1997). Neurobiological bases of behavioral development in the first year. Neuropediatrics 28, 296-306.

Hevner, R. F. (2000). Development of connections in the human visual system during fetal mid-gestation: a DiI-tracing study. J. Neuropathol. Exp. Neurol. 59, 385-392.

Holmes, G. L. (2005). Effects of seizures on brain development: lessons from the laboratory. Pediatr. Neurol. 33, 1-11.

Huttenlocher, P. R., and Dabholkar,A.S. (1997). Regional differences in synaptogenesis in human cerebral cortex. J. Comp. Neurol. 387, 167-178.

Jensen, F. E. (2009). Developmental factors in the pathogenesis of neonatal seizures. J. Pediatr. Neurol. 7, 5-12.

Kahle, K. T., Barnett, S. M., Sassower, K. C., and Staley, K. J. (2009). Decreased seizure activity in a human neonate treated with bumetanide, an inhibitor of the $\mathrm{Na}(+)-\mathrm{K}(+)-2 \mathrm{Cl}(-)$ cotransporter NKCC1. J. Child Neurol. 24, 572-576. 
Khazipov, R., Esclapez, M., Caillard, O., Bernard, C., Khalilov, I., Tyzio, R., et al. (2001). Early development of neuronal activity in the primate hippocampus in utero. J. Neurosci. 21, 9770-9781.

Kilb, W., Sinning, A., and Luhmann, H. J. (2007). Modelspecific effects of bumetanide on epileptiform activity in the in-vitro intact hippocampus of the newborn mouse. Neuropharmacology 53, 524-533.

Kim, J. S., Kondratyev, A., Tomita, Y., and Gale, K. (2007). Neurodevelopmental impact of antiepileptic drugs and seizures in the immature brain. Epilepsia 48(Suppl.5), 19-26.

Kostovic, I., and Jovanov-Milosevic, N. (2006). The development of cerebral connections during the first 20-45 weeks' gestation. Semin. Fetal Neonatal Med. 11, 415-422.

Kostovic, I., and Judas, M. (2002). Correlation between the sequential ingrowth of afferents and transient patterns of cortical lamination in preterm infants. Anat. Rec. 267, 1-6.

Kostovic, I., and Rakic, P. (1990). Developmental history of the transient subplate zone in the visual and somatosensory cortex of the macaque monkey and human brain. J. Comp. Neurol. 297, 441-470.

Kretschmann, H. J., Kammradt, G., Krauthausen, I., Sauer, B., and Wingert, F. (1986). Growth of the hippocampal formation in man. Bibl. Anat. 28, 27-52.

Letinic, K., and Kostovic, I. (1997). Transient fetal structure, the gangliothalamic body, connects telencephalic germinal zone with all thalamic regions in the developing human brain. J. Comp. Neurol. 384, 373-395.

Letinic, K., and Rakic, P. (2001). Telencephalic origin of human thalamic GABAergic neurons. Nat. Neurosci. 4, 931-936.

Levitt, P. (2003). Structural and functional maturation of the developing primate brain. J. Pediatr. 143 , S35-S45.

Mares, P. (2009). Age- and dose-specific anticonvulsant action of bumetanide in immature rats. Physiol. Res. 58, 927-930.

Mazarati,A., Shin, D., and Sankar, R. (2009). Bumetanide inhibits rapid kindling in neonatal rats. Epilepsia 50, 2117-2122.
Miller, S. P., Weiss, J., Barnwell, A., Ferriero, D. M., LatalHajnal, B., Ferrer-Rogers, A., et al. (2002). Seizureassociated brain injury in term newborns with perinatal asphyxia. Neurology 58, 542-548.

Molliver, M. E., Kostovic, I., and van der, L. H. (1973). The development of synapses in cerebral cortex of the human fetus. Brain Res. 50, 403-407.

Painter, M. J., Scher, M. S., Stein, A. D., Armatti, S., Wang, Z., Gardiner, J. C., et al. (1999). Phenobarbital compared with phenytoin for the treatment of neonatal seizures. N. Engl. J. Med. 341, 485-489.

Pangratz-Fuehrer, S., and Hestrin, S. (2011). Synaptogenesis of electrical and GABAergic synapses of fast-spiking inhibitory neurons in the neocortex. J. Neurosci. 31, 10767-10775.

Price, D. J., Aslam, S., Tasker, L., and Gillies, K. (1997) Fates of the earliest generated cells in the developing murine neocortex. J. Comp. Neurol. 377, 414-422.

Raedler, E., Raedler, A., and Feldhaus, S. (1980). Dynamical aspects of neocortical histogenesis in the rat. Anat. Embryol. 158, 253-269.

Romijn, H. J., Hofman, M. A., and Gramsbergen, A. (1991). At what age is the developing cerebral cortex of the rat comparable to that of the full-term newborn human baby? Early Hum. Dev. 26, 61-67.

Ronen, G. M., Buckley, D., Penney, S., and Streiner, D. L. (2007). Long-term prognosis in children with neonatal seizures: a population-based study. Neurology 69, 1816-1822.

Schlumpf, M., Shoemaker, W. J., and Bloom, F. E. (1980). Innervation of embryonic rat cerebral cortex by catecholamine-containing fibers. J. Comp. Neurol. 192 361-376.

Silverstein, F. S., Jensen, F. E., Inder, T., Hellstrom-Westas, L., Hirtz, D., and Ferriero, D. M. (2008). Improving the treatment of neonatal seizures: national Institute of Neurological Disorders and Stroke workshop report. J. Pediatr. 153, 12-15.

Vento, M., de Vries, L. S., Alberola, A., Blennow, M. Steggerda, S., Greisen, G., et al. (2010). Approach to seizures in the neonatal period: a European perspective. Acta Paediatr. 99, 497-501.
Wang, D. D., and Kriegstein, A. R. (2011). Blocking Early GABA Depolarization with Bumetanide Results in Permanent Alterations in Cortical Circuits and Sensorimotor Gating Deficits. Cereb. Cortex 21, 574-587.

Wood, J. G., Martin, S., and Price, D. J. (1992). Evidence that the earliest generated cells of the murine cerebral cortex form a transient population in the subplate and marginal zone. Brain Res. Dev. Brain Res. 66, 137-140.

Wood, S. L., Beyer, B. K., and Cappon, G. D. (2003). Species comparison of postnatal CNS development: functional measures. Birth Defects Res. B Dev. Reprod. Toxicol. 68, 391-407.

Zagon, I. S., and McLaughlin, P. J. (1977). Effect of chronic maternal methadone exposure on perinatal development. Biol. Neonate 31, 271-282.

Zecevic, N. (1998). Synaptogenesis in layer I of the human cerebral cortex in the first half of gestation. Cereb. Cortex 8, 245-252.

Zecevic, N., Bourgeois, J. P., and Rakic, P. (1989). Changes in synaptic density in motor cortex of rhesus monkey during fetal and postnatal life. Brain Res. Dev. Brain Res. 50, 11-32.

Zeng, S. J., Lin, Y. T., Tian, C. P., Song, K. J., Zhang, X. W., and Zuo, M. X. (2009). Evolutionary significance of delayed neurogenesis in the core versus shell auditory areas of Mus musculus. J. Comp. Neurol. 515, 600-613.

Received: 28 January 2013; accepted: 01 April 2013; published online: 15 April 2013.

Citation: Pressler Rand Auvin S (2013) Comparison of brain maturation among species: an example in translational research suggesting the possible use of bumetanide in newborn. Front. Neurol. 4:36. doi: 10.3389/fneur.2013.00036 This article was submitted to Frontiers in Epilepsy, a specialty of Frontiers in Neurology.

Copyright $\odot 2013$ Pressler and Auvin. This is an open-access article distributed under the terms of the Creative Commons Attribution License, which permits use, distribution and reproduction in other forums, provided the original authors and source are credited and subject to any copyright notices concerning any third-party graphics etc. 